\title{
Bupropion interferes with the image diagnosis of Parkinson's disease
}

\author{
This article was published in the following Dove Press journal: \\ Neuropsychiatric Disease and Treatment \\ 19 October 2017 \\ Number of times this article has been viewed
}

\author{
Chieh-Hsin Lin ${ }^{1-3}$ \\ Hsien-Yuan Lane ${ }^{2,4}$ \\ 'Department of Psychiatry, Kaohsiung \\ Chang Gung Memorial Hospital, \\ Chang Gung University College \\ of Medicine, Kaohsiung, Taiwan, \\ ${ }^{2}$ Graduate Institute of Biomedical \\ Sciences, China Medical University, \\ Taichung, Taiwan, ${ }^{3}$ Center for General \\ Education, Cheng Shiu University, \\ Kaohsiung, Taiwan, ${ }^{4}$ Department of \\ Psychiatry, China Medical University \\ Hospital, Taichung, Taiwan
}

\begin{abstract}
Major depressive disorder (MDD) and Parkinson's disease (PD) share symptoms such as tremor. Bupropion, a norepinephrine-dopamine reuptake inhibitor, shows weak dopamine transporter (DAT) occupancy. We report here on a patient with MDD whose hand tremors might have been misdiagnosed as PD by single-photon emission computed tomography (SPECT) under bupropion use. A 66-year-old male patient with MDD had been receiving bupropion $150 \mathrm{mg}$ per day for 6 months. His mood symptoms improved partially with bupropion treatment, however, hand tremors persisted. The neurological examination revealed bilateral hand tremors without other typical signs for PD. The SPECT using Tc-99m TRODAT-1 revealed decreased DAT binding capacity in bilateral striata. Under the impression of atypical PD, the patient was advised to take anti-Parkinson's drug. Bupropion was discontinued for 14 days to confirm the test. The follow-up SPECT after 14 days found improvement for the uptake ratio of striata. From then onward, the anti-Parkinson's drug was not used due to the lack of typical sign(s) for PD. The patient's mental and physical status remained stable without worsening of hand tremors during follow-up. Tc-99m TRODAT-1 SPECT is helpful for the evaluation of DAT and the diagnosis of PD. However, the interpretation of the SPECT image might be biased by the use of certain drugs such as bupropion for its binding to DAT. Bupropion may decrease the Tc- $99 \mathrm{~m}$ TRODAT-1 binding to DAT. The effect of drugs on DAT should be carefully assessed while interpreting the Tc-99m TRODAT-1 image. Our findings suggest that all drugs that may alter DAT occupancy should be listed as the reference for Tc-99m TRODAT-1 image reading.
\end{abstract}

Keywords: bupropion, dopamine transporter, single-photon emission computed tomography, Parkinson's disease, Tc-99m TRODAT-1

\section{Introduction}

Major depressive disorder (MDD) and Parkinson's disease (PD) are common neuropsychiatric disorders in the elderly. MDD and PD share several symptoms, such as psychomotor retardation, tremor, anxiety, and insomnia. ${ }^{1}$ Currently, the diagnosis of PD mainly relies on clinical assessment. However, the role of brain images becomes increasingly important. Single-photon emission computed tomography (SPECT) using Tc-99m TRODAT for binding to dopamine transporter (DAT) is a commonly used image tool for PD in addition to computed tomography, magnetic resonance imaging and other functional imaging tools.

Bupropion, a norepinephrine-dopamine reuptake inhibitor, is a commonly prescribed antidepressant. Bupropion demonstrated weak DAT occupancy. ${ }^{2,3}$ However, some studies failed to find an increase of dopamine level in the brain after oral treatment with bupropion. ${ }^{4}$ The inconclusive findings raise a question: is the low DAT occupancy of bupropion sufficient to cause clinical and image change? Here, we
Correspondence: Hsien-Yuan Lane Department of Psychiatry, China Medical University Hospital, Number 2, Yuh-Der Road, Taichung 404, Taiwan Email hylane@gmail.com (c) (1) (5) 2017 Lin and Lane. This work is published and licensed by Dove Medical Press Limited. The full terms of this license are available at https://www.dovepress.com/terms.php (c) $\mathrm{BY}$ and incorporate the Creative Commons Attribution - Non Commercial (unported, v3.0) License (http://creativecommons.org/licenses/by-nc $/ 3.0 /)$. By accessing the work you hereby accept the Terms. Non-commercial uses of the work are permitted without any further permission from Dove Medical Press Limited, provided the work is properly attributed. For permission for commercial use of this work, please see paragraphs 4.2 and 5 of our Terms (https://www.dovepress.com/terms.php). 
report a patient with MDD whose hand tremors might have been misdiagnosed as PD because of bupropion use.

\section{Case report}

A 66-year-old male manifested psychiatric symptoms such as anxiety, insomnia, depressed mood, hypochondriasis, and hand tremors. He had been receiving bupropion $150 \mathrm{mg}$ per day and clonazepam $1 \mathrm{mg}$ per day for 6 months, since he was 65 years of age, because of the diagnosis of MDD. The patient's mood symptoms such as depression and anxiety partially improved with bupropion treatment. He had no other physical illness and had not been taking other medications except bupropion and clonazepam. The patient worried about the possibility of PD and underwent neurological examination and brain images tests. The neurological examination revealed bilateral hand tremors that presented during both resting and voluntary movement without other typical signs for PD such as pill-rolling tremor, bradykinesia, rigidity or postural instability. The neurological examination did not favor PD. The SPECT using Tc-99m TRODAT-1 showed decreased DAT binding capacity in bilateral striata (uptake ratio of striata: right 0.31 ; left 0.27 , Figure $1 \mathrm{~A}$ ) and immeasurable visual score of striata due to an atypical pattern of striatal uptake. The uptake ratio was calculated by the following equation: (The average count density of striatum - the average count density of the reference regions)/the average count density of the reference regions. The reference regions were the cerebellar and the occipital cortex. The striatum is marked by the dotted line in Figure 1. Under the impression of atypical PD, the patient was advised to take levodopa combined with benserazide by the neurologist. Discontinuation of bupropion for 14 days for the confirmation of the test was suggested by the psychiatrist. The follow-up SPECT after 14 days showed improvement in the uptake ratio of striata (right 0.47; left 0.56, Figure 1B) and the visual score of striata (Score 0 with intact striatal shape). The patient's gait was steady, and his muscle power of limbs was normal. Due to the lack of typical sign for PD, anti-Parkinson's drug was not used. During the follow-up period, the patient's mental and physical status remained stable without worsening of hand tremors.

\section{Discussion}

The differential diagnosis between MDD and neurodegenerative diseases, including PD and Alzheimer's disease is sometimes challenging. Tc-99m TRODAT-1 SPECT is very
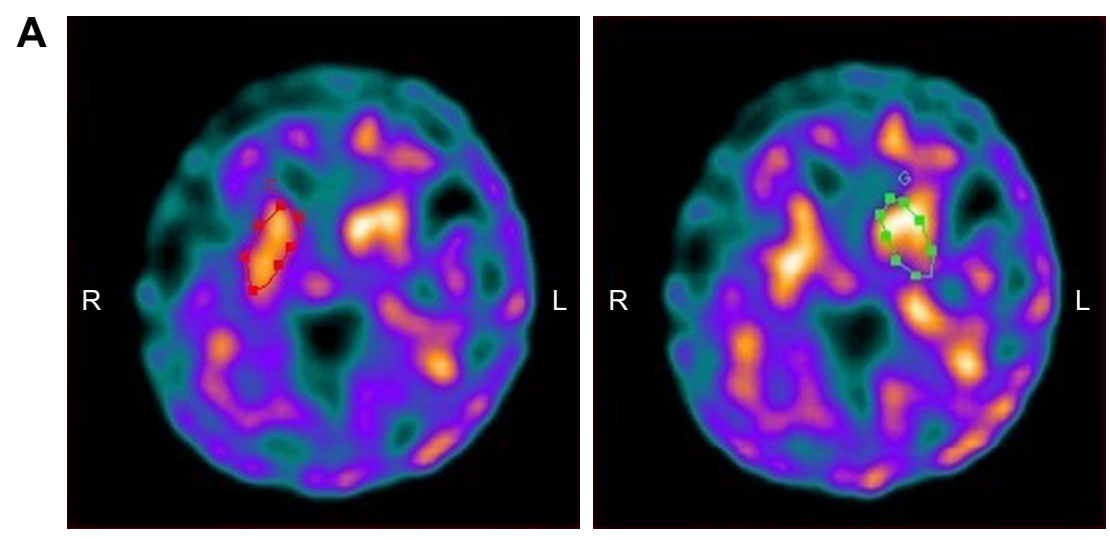

B
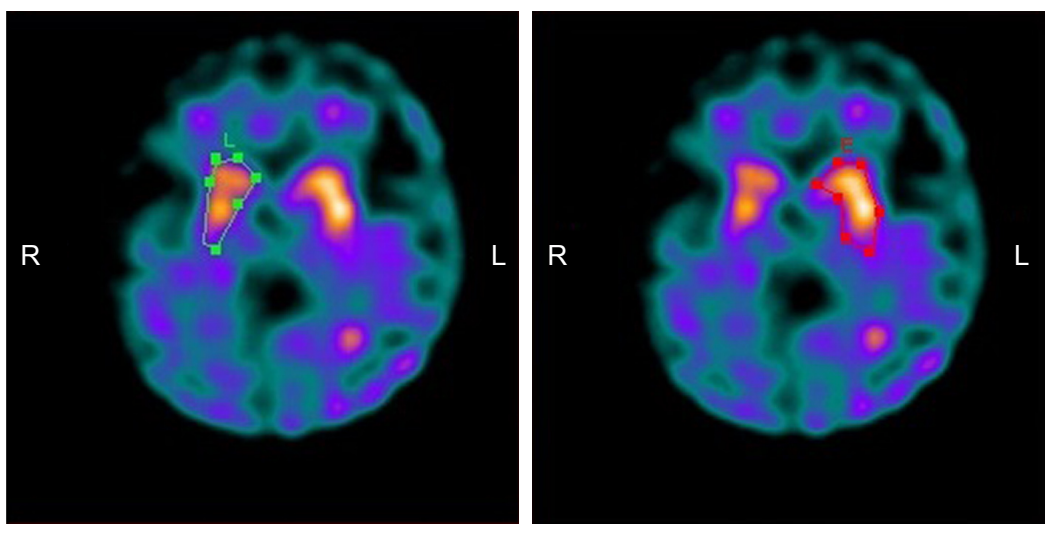

Figure I SPECT images using Tc-99m TRODAT-I.

Notes: (A) SPECT images under bupropion use. (B) SPECT images after discontinuation of bupropion for 14 days. The striatum is marked by the dotted line. Abbreviations: L, left; R, right; SPECT, single-photon emission computed tomography. 
helpful for the evaluation of DAT. However, the interpretation of the image might be biased by the use of concomitant drugs such as bupropion for its binding to DAT. ${ }^{5}$ In this case report, we described that the use of bupropion might lead to misdiagnosis of PD by the decreased DAT binding capacity.

Some substrates such as cocaine and amphetamine, methylphenidate, dopamine releasers, transport inhibitors, allosteric modulators and even HIV-1 Tat protein ${ }^{6}$ can bind to the DAT. Bupropion, as a weak norepinephrine-dopamine reuptake inhibitor, may decrease the Tc-99m TRODAT-1 binding to DAT, ${ }^{7}$ while some selective serotonin reuptake inhibitors may increase its binding. ${ }^{8}$ Bupropion has been found to be a releasing agent of dopamine and norepinephrine. ${ }^{9}$ The major metabolite of bupropion, hydroxybupropion, acts as a selective norepinephrine reuptake inhibitor and nicotinic acetylcholine receptor antagonist. ${ }^{4}$

In this case, the DAT binding capacities were still lower than the reference range at the follow-up SPECT image. A possibility is the dysregulation of DAT found in depressed patients. ${ }^{10}$ Another possibility is that the metabolites of bupropion can reach the plasma concentrations 16-20 times greater than those of bupropion itself. ${ }^{4} \mathrm{~A}$ follow-up SPECT after longer discontinuation of bupropion may be needed.

The effect of drugs on DAT should be carefully assessed while we interpret the Tc-99m TRODAT-1 image. Clinicians need to integrate complete information, including medication use, associated symptoms and signs, and laboratory tests for the diagnosis of PD. Moreover, all drugs that may alter DAT occupancy should be listed as the reference for TRODAT image reading.

\section{Acknowledgment}

A written informed consent has been provided by the patient to have the case details and SPECT images published.

\section{Disclosure}

The authors report no conflicts of interest in this work.

\section{References}

1. Hesdorffer DC. Comorbidity between neurological illness and psychiatric disorders. CNS spectrums. 2016;21(3):230-238.

2. Learned-Coughlin SM, Bergstrom M, Savitcheva I, Ascher J, Schmith VD, Langstrom B. In vivo activity of bupropion at the human dopamine transporter as measured by positron emission tomography. Biol Psychiatry. 2003;54(8):800-805.

3. Meyer JH, Goulding VS, Wilson AA, Hussey D, Christensen BK, Houle S. Bupropion occupancy of the dopamine transporter is low during clinical treatment. Psychopharmacology (Berl). 2002;163(1): 102-105.

4. Dwoskin LP. Preface. Emerging targets and therapeutics in the treatment of psychostimulant abuse. Adv Pharmacol. 2014;69:xi-xiii.

5. Argyelan M, Szabo Z, Kanyo B, et al. Dopamine transporter availability in medication free and in bupropion treated depression: a $99 \mathrm{mTc}-$ TRODAT-1 SPECT study. J Affect Disord. 2005;89(1-3):115-123.

6. Midde NM, Huang X, Gomez AM, Booze RM, Zhan CG, Zhu J. Mutation of tyrosine 470 of human dopamine transporter is critical for HIV-1 Tat-induced inhibition of dopamine transport and transporter conformational transitions. J Neuroimmune Pharmacol. 2013;8(4): 975-987.

7. Hsiao MC, Lin KJ, Liu CY, Schatz DB. The interaction between dopamine transporter function, gender differences, and possible laterality in depression. Psychiatry Res. 2013;211(1):72-77.

8. Dresel SH, Kung MP, Huang X, et al. In vivo imaging of serotonin transporters with [99mTc]TRODAT-1 in nonhuman primates. Eur $J$ Nucl Med. 1999;26(4):342-347.

9. Arias HR, Santamaria A, Ali SF. Pharmacological and neurotoxicological actions mediated by bupropion and diethylpropion. Int Rev Neurobiol. 2009;88:223-255.

10. Brunswick DJ, Amsterdam JD, Mozley PD, Newberg A. Greater availability of brain dopamine transporters in major depression shown by [99m Tc]TRODAT-1 SPECT imaging. Am J Psychiatry. 2003; 160(10):1836-1841
Neuropsychiatric Disease and Treatment

\section{Publish your work in this journal}

Neuropsychiatric Disease and Treatment is an international, peerreviewed journal of clinical therapeutics and pharmacology focusing on concise rapid reporting of clinical or pre-clinical studies on a range of neuropsychiatric and neurological disorders. This journal is indexed on PubMed Central, the 'PsycINFO' database and CAS,

\section{Dovepress}

and is the official journal of The International Neuropsychiatric Association (INA). The manuscript management system is completely online and includes a very quick and fair peer-review system, which is all easy to use. Visit http://www.dovepress.com/testimonials.php to read real quotes from published authors. 